\title{
IDENTIFIKASI JALUR DAN TEMPAT EVAKUASI TSUNAMI BERDASARKAN FEMA P646 PADA OBJEK-OBJEK WISATA PANTAI DI KABUPATEN GUNUNGKIDUL
}

\author{
(Studi Kasus: Pantai Nguyahan, Ngobaran dan Ngrenehan)
}

\author{
Limpat Wibowo Aji \\ Jurusan Teknik Sipil Universitas Gunung Kidul \\ Email: limpatwibowo@gmail.com
}

\begin{abstract}
ABSTRAK
Jumlah pengunjung maksimal objek wisata pantai di Kabupaten Gunungkidul antara Tahun 2014-2017 sejumlah 18.369 jiwa per bulan, sehingga jika terjadi tsunami potensi korban sangat besar, maka untuk meminimalkan korban jiwa saat terjadi tsunami diperlukan suatu kebijakan untuk pengurangan risiko terhadap bencana tersebut dengan strategi penyelamatan yang komprehensif dan upayanya menyediakan Sistem Peringatan Dini Tsunami. Tujuan penelitian adalah menentukan tempat evakuasi tsunami pada objek-objek wisata pantai di Kabupaten Gunungkidul berdasarkan FEMA P646 dan membandingkan dengan hasil penentuan tempat evakuasi tsunami yang dilakukan oleh BPBD Kabupaten Gunungkidul kesesuaian dengan pedoman FEMA P646. Penelitian ini menggunakan metode kuantitatif dengan teknik analisis deskriptif yaitu menganalisis jalur dan tempat evakuasi (TE) dengan berpedoman dengan FEMA P646 untuk menentukan tempat evakuasi tsunami, ketinggian elevasi merupakan bahan dasar dari analisis yang dilakukan. Oleh karena itu, perlu dilakukan pengumpulan data ketinggian elevasi, waktu tiba tsunami, proyeksi jumlah pengunjung untuk menunjang analisis. Titik evakuasi (TE)/titik aman dibutuhkan dalam proses evakuasi, maka analisis mengenai area evakuasi tersebut perlu dilakukan. Proses analisis dilakukan dengan terlebih dahulu menentukan ketinggian elevasi titik aman. Ketinggian elevasi titik aman dapat berupa titik yang berada di luar jangkauan gelombang tsunami ataupun area yang berada di dalam area genangan tsunami. Hasil penelitian ini adalah nilai ketinggian titik kumpul/titik aman 25 meter dari permukaan laut menjadi dasar untuk menyelamatkan diri, jika dihubungkan dengan kecepatan orang berjalan (kondisi lemah), maka waktu kedatangan/waktu tiba tsunami didapat tidak lebih dari 1 jam, hal ini masih dalam batasan sesuai dengan Federal Emergency Management Agency (FEMA P-646, 2008), lokasi titik kumpul/titik aman evakuasi tsunami tersebut bisa digunakan penyelamatan pertama korban tsunami dengan mempertimbangkan waktu kedatangan tsunami, sedangkan pada BPBD untuk penampungan korban tsunami menggunakan fasilitas umum walaupun jaraknya jauh dan mengindahkan waktu kedatangan tsunami.
\end{abstract}

Kata kunci: elevasi, evakuasi, identifikasi, pantai, tsunami

\section{ABSTRACT}

The maximum number of monthly visitors to the tourism coasts in Gunungkidul Regency between 2014 and 2017 is 18.369 people. Those Indian Ocean beaches that are in the southern sides of the Island of Java are prone to tsunami disaster. However, there were no systematic and scientific study to make analysis of the tsunami disaster mitigation to those tourism beaches. Therefore, a series of policies with comprehensive rescue strategies and efforts to minimize the risk of the tsunami disaster is required. The purpose of this study was to determine places of tsunami evacuation for the tourism beaches in Gunungkidul Regency based on P646 of FEMA (Federal Emergency Management Agency) and compare them with the result of the determine places of tsunami evacuation conducted by BPBD (Local Disaster Management Authority) of Gunungkidul Regency, Yogyakarta. This purpose also includes the want of the authors to implement the method of this study to be the policy of tsunami mitigation for similar tourism beaches in the Special Territory of Yogyakarta as well as similar beaches in Indonesia. This study uses quantitative method with descriptive analysis technique that is analyzing the paths and places of tsunami evacuation based on P646 of FEMA. Given location elevation is the basic ingredient of the analysis, and therefore, elevation data, tsunami arrival time, projected number of visitors to support the analysis need to be gathered. The analysis of the evacuation areas is required to determine the evacuation places that are safe points in the evacuation process. An elevation of a safe point elevation can be a point that is beyond the reach of tsunami waves or safe areas within the tsunami pool areas. The results of this study are the height of the gathering point / safe point 25 meters above sea level to be the basis for saving themselves, if connected with the speed of walking (weak condition), then the arrival time / arrival time of the tsunami is not more than 0.5 hours. This is still within limits in accordance with the Federal Emergency Management Agency (FEMA P-646, 2008), the location of the gathering point / tsunami evacuation safe point can be used as the first rescue of tsunami victims by considering the arrival time of the tsunami. On the other hand, BPBD accommodate tsunami victims using public facilities even though they are far away and heed the arrival time of the tsunami. 


\section{PENDAHULUAN}

Wilayah Kabupaten Gunungkidul terletak antara $7^{\circ} 46^{\prime}-8^{\circ} 09^{\prime}$ Lintang Selatan dan $110^{\circ} 21^{\prime}-110^{\circ} 50^{\prime}$ Bujur Timur, yang berbatasan dengan Kabupaten Klaten dan Kabupaten Sukoharjo di sebelah utara; Kabupaten Wonogiri di sebelah timur; Samudra Hindia 4 mil dari garis pantai di sebelah selatan; Kabupaten Sleman dan Kabupaten Bantul di sebelah barat. Luas Wilayah Kabupaten Gunungkidul tercatat $1.485,36 \mathrm{~km}^{2}$ yang secara administratif dibagi menjadi 18 kecamatan, 144 desa dan 1.431 dusun (BPBD, 2012). sebagaimana dapat dilihat pada Gambar 1.

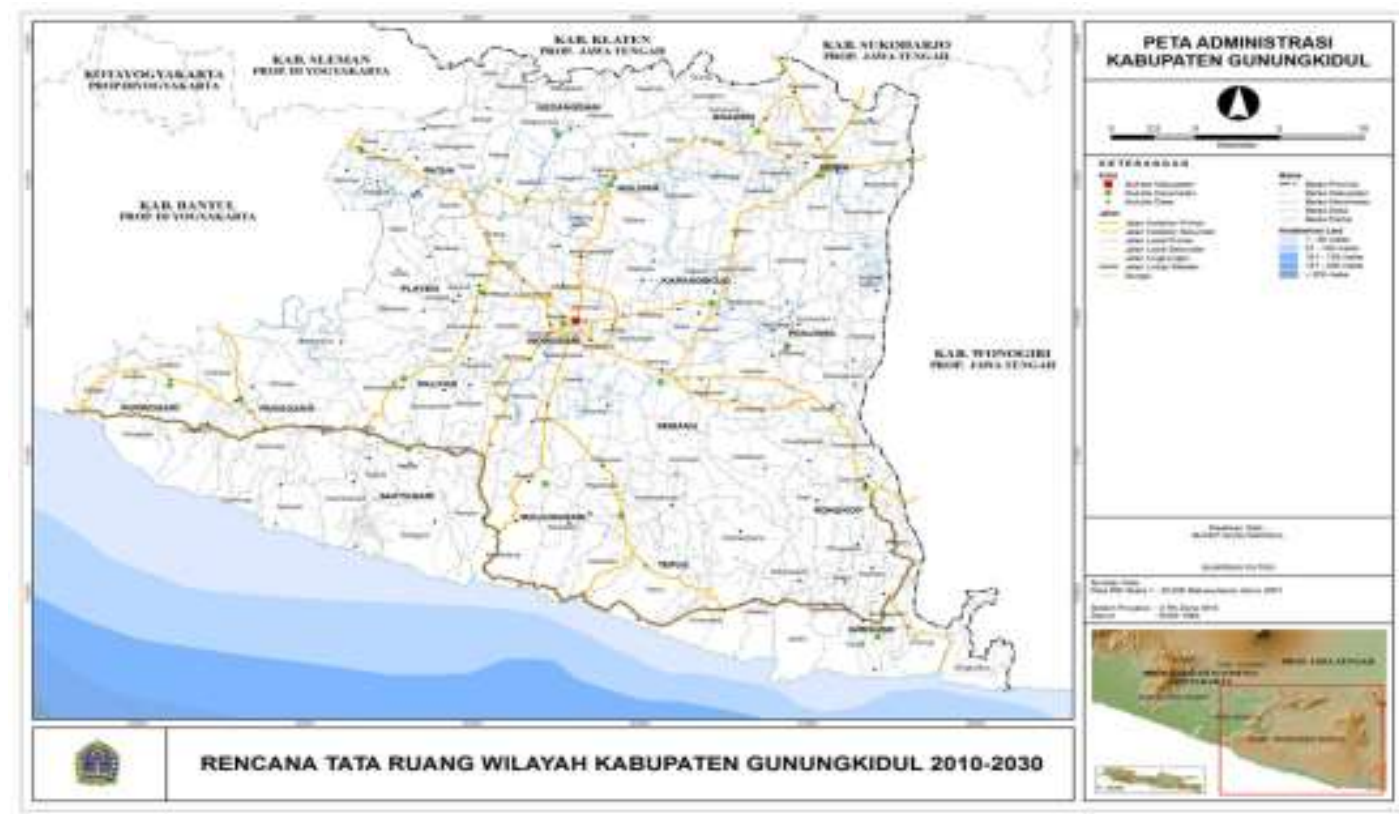

Gambar 1. Peta Administrasi Kabupaten Gunungkidul (http://google.com)

Kondisi geologis dan geografis yang beragam di Kabupaten Gunungkidul selain memiliki potensi yang dapat dikembangkan dalam perencanaan pembangunan wilayah, juga menyimpan ancaman bencana dalam kehidupan masyarakat. Ancaman bencana di Kabupaten Gunungkidul sangat kompleks karena dipengaruhi oleh kondisi geografis, geologis serta kapasitas dan kerentanan masyarakat. $\mathrm{Di}$ wilayah utara, tanah longsor dan gempa bumi menjadi ancaman utama disebabkan oleh topografi bergunung dengan susunan batuan tua yang lapuk serta terletak dekat dengan daerah patahan aktif, selain juga ancaman bencana kekeringan. Wilayah tengah dan selatan yang merupakan daerah peralihan dan wilayah karst, memiliki ancaman bencana berupa kekeringan, puting beliung, gempa bumi serta tsunami di sepanjang wilayah pesisir selatan. Oleh karena itu setiap proses pembangunan di wilayah harus berwawasan pengurangan risiko terhadap ancaman bencana tersebut (BPBD, 2012).

Wilayah ancaman bencana gempa bumi yang berpotensi tsunami di Kabupaten Gunungkidul terletak di pesisir selatan yang berbatasan dengan Samudera Indonesia. Samudera Indonesia di selatan pulau jawa adalah merupakan pertemuan lempeng Eurasia dan Indoaustralia yang merupakan sumber terjadinya gempa bumi tektonik. Letak pertemuan lempeng 
di tengah laut menyebakan wilayah pesisir menjadi rentan terhadap bahaya tsunami yang diakibatkan oleh pergeseran lempeng tersebut (BPBD, 2012).

Kabupaten Gunungkidul memiliki wilayah pesisir dengan panjang pantai $\pm 72 \mathrm{~km}$ yang meliputi 6 kecamatan (Purwosari, Panggang, Saptosari, Tanjungsari, Tepus dan Girisubo) dan terdiri dari 19 desa yang berbatasan dengan laut. Pantai Nguyahan, Pantai Ngobaran, dan Pantai Ngrenehan merupakan kawasan pantai yang memiliki aktivitas manusia cukup tinggi baik dari sektor pariwisata dan sektor perikanan (BPBD, 2012). Lokasi objek wisata pantai pada penelitian ini dapat dilihat pada Gambar 2.

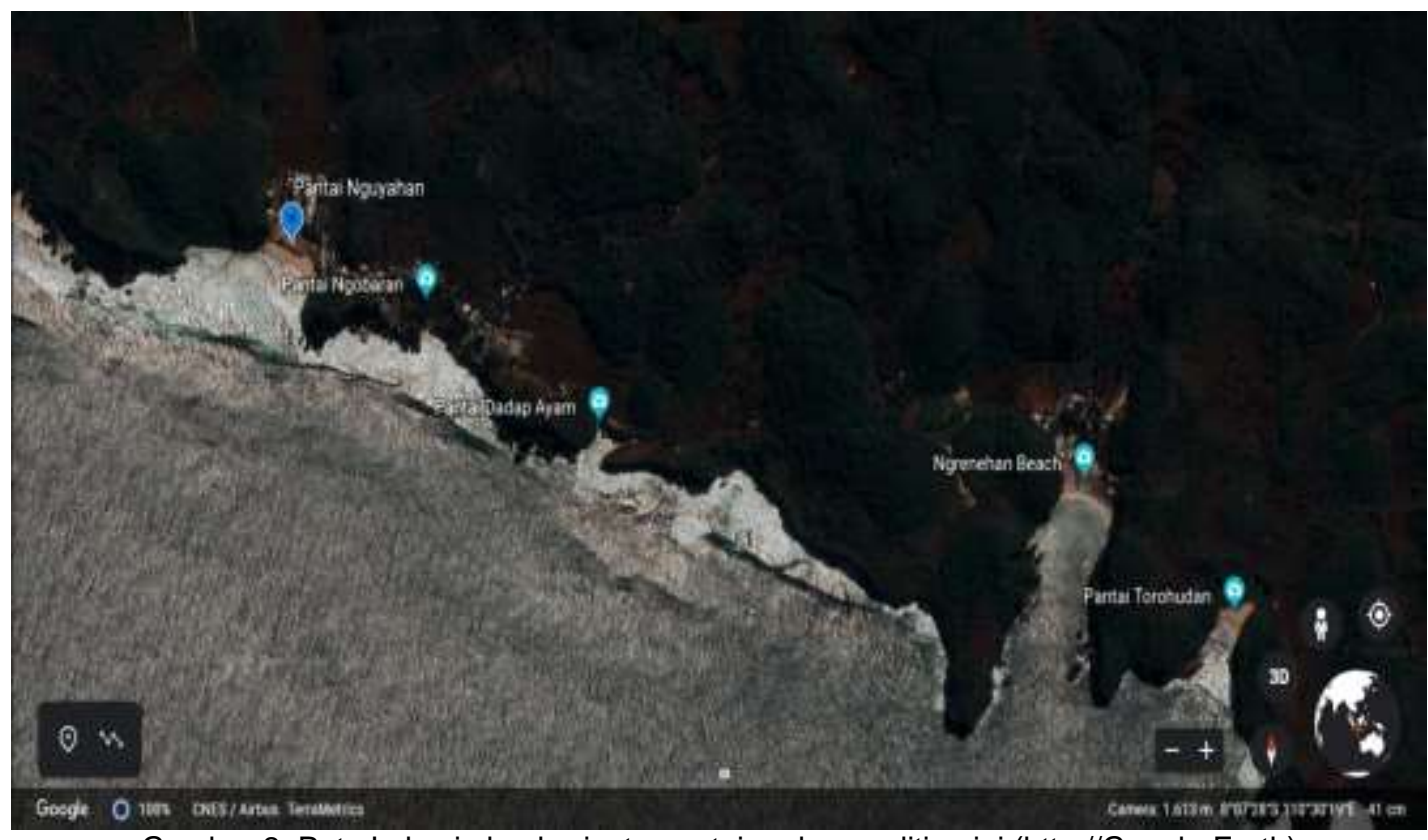

Gambar 2. Peta Lokasi obyek wisata pantai pada penelitian ini (http://Google Earth)

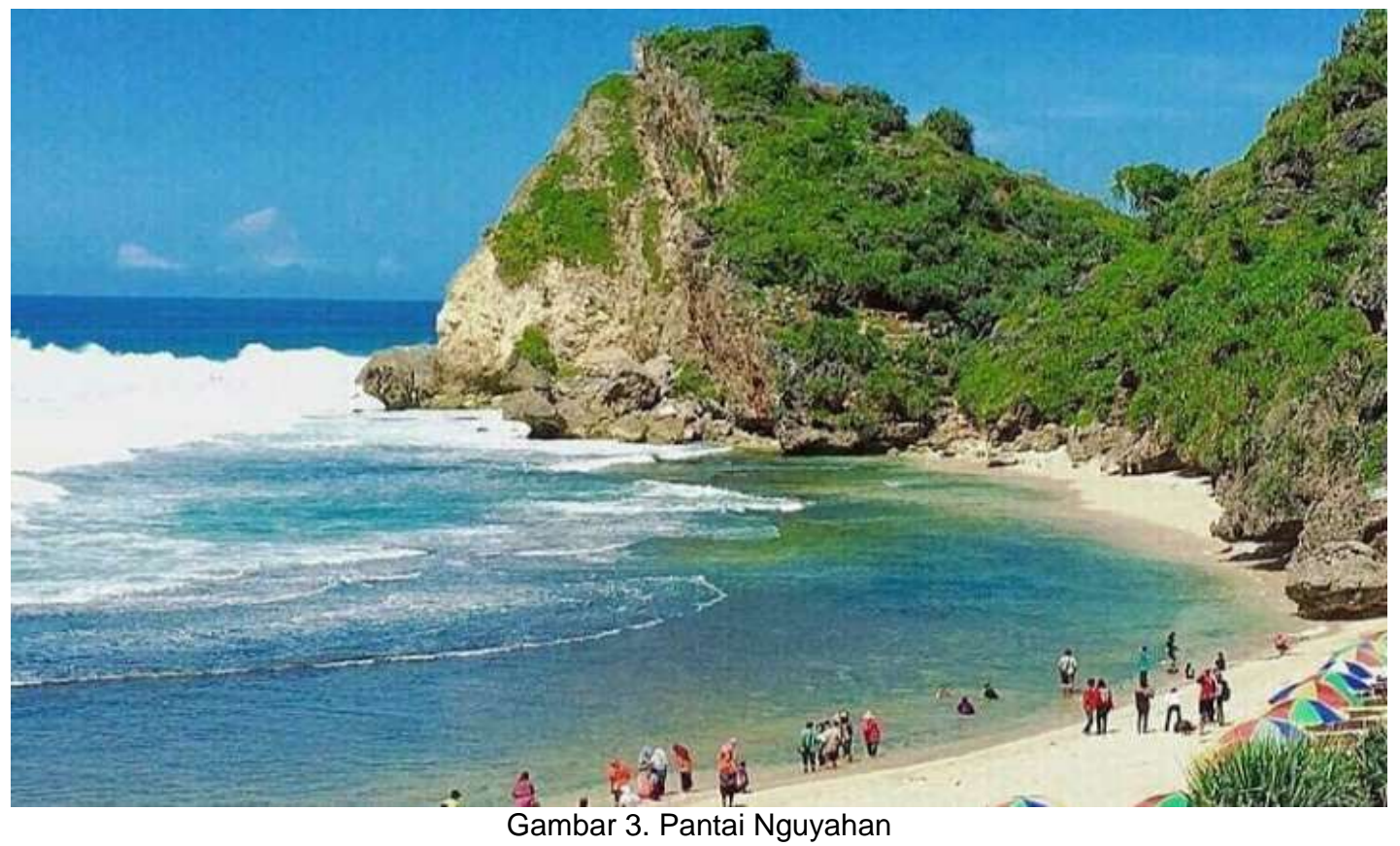




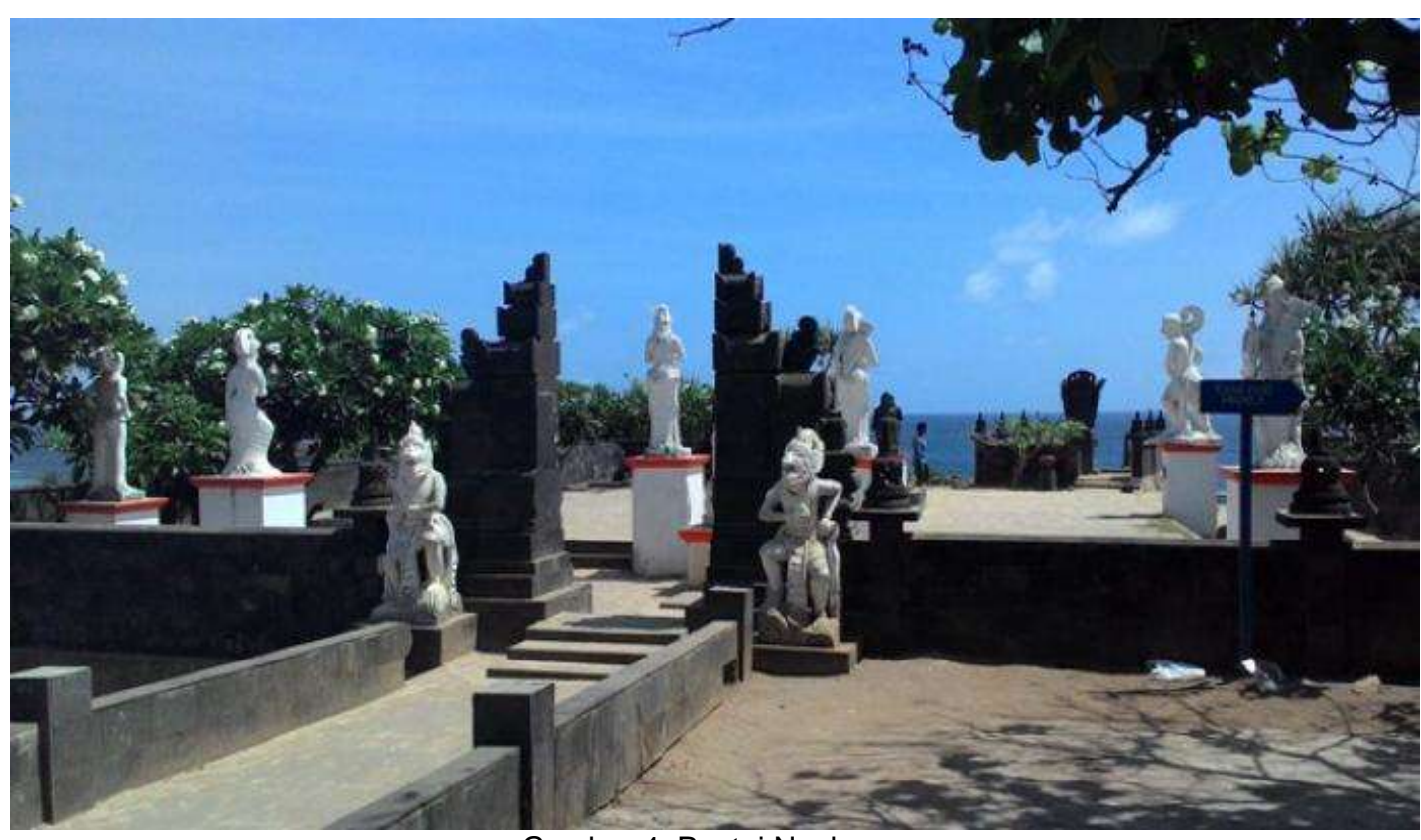

Gambar 4. Pantai Ngobaran

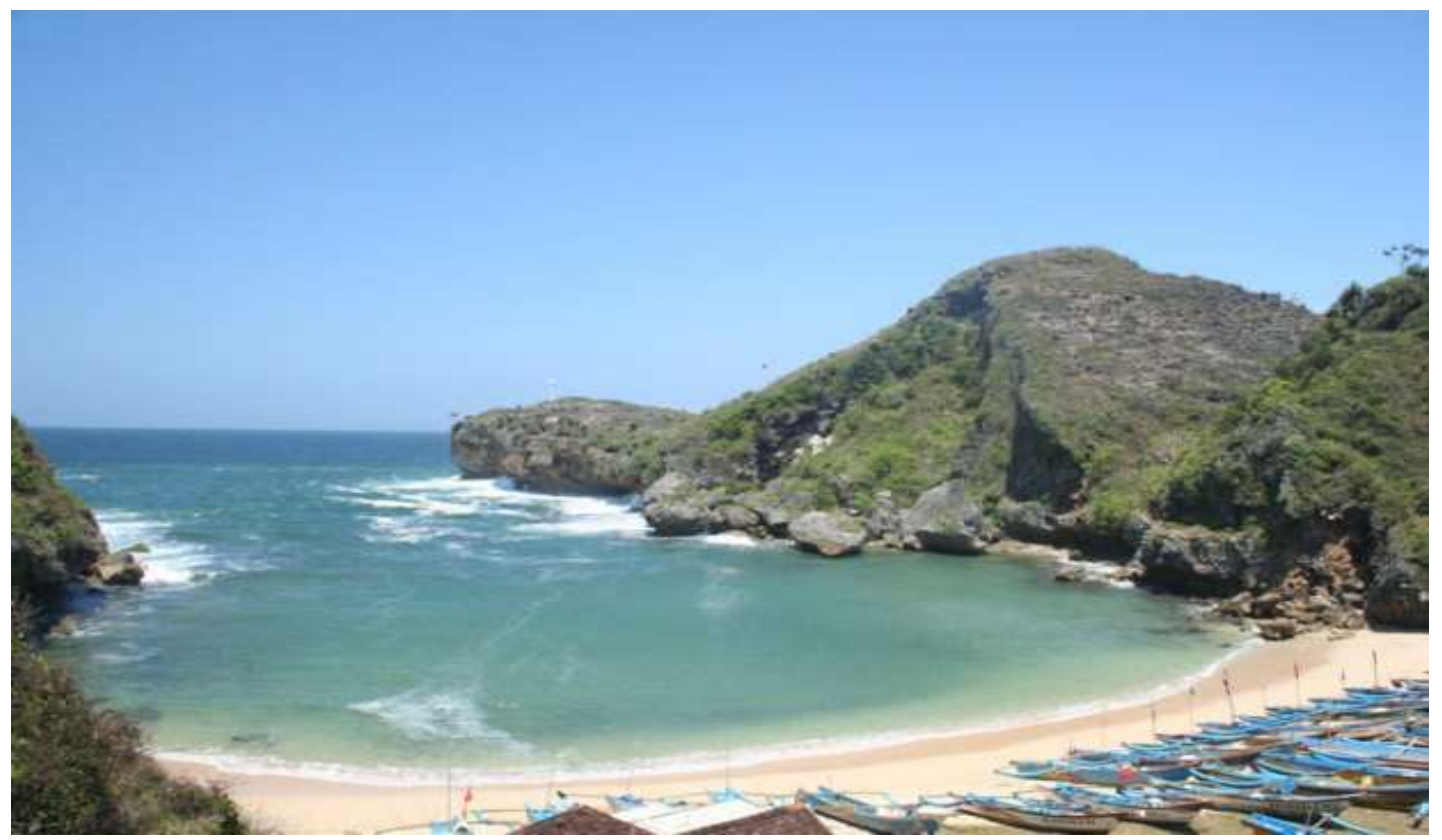

Gambar 5. Pantai Ngrenehan

Jumlah pengunjung pada Pantai Nguyahan-Ngobaran-Ngrenehan di Kabupaten Gunungkidul pada kondisi puncak liburan (DISBUDPAR, 2016). sebagaimana bisa dilihat pada Tabel 1 . berikut.

\begin{tabular}{|c|c|}
\hline Nama Pantai & $\begin{array}{l}\text { Jumlah Pengunjung Liburan } \\
\text { Puncak (per hari) (orang) }\end{array}$ \\
\hline Nguluran & \multirow{3}{*}{$18.369 / 8=2.296$} \\
\hline Gesing & \\
\hline Butuh & \\
\hline & $18.369 / 8=2.296$ \\
\hline
\end{tabular}

Dengan mempertimbangkan kurang lebih 28\% (150 dari 530) kota/kabupaten di 
Indonesia memiliki risiko tinggi terhadap tsunami termasuk Wilayah Propinsi Daerah Istimewa Yogyakarta yaitu Kabupaten Gunungkidul memiliki risiko tinggi terhadap tsunami, maka untuk meminimalkan risiko korban jiwa saat terjadi tsunami diperlukan suatu kebijakan pengurangan risiko bencana dengan strategi penyelamatan yang komprehensif (BNPB, 2009). Selain dibutuhkan keberadaan Sistem Peringatan Dini Tsunami, diperlukan pulaupaya pengurangan risiko bencana tsunami yaitu dalam bentuk identifikasi jalur dan tempat evakuasi tsunami di kawasan rawan tsunami; objek-objek wisata pantai di Gunungkidul sebagai tempat evakuasi dan berlindung saat bencana tsunami terjadi. Identifikasi jalur dan tempat evakuasi yang digunakan sebagai tempat perlindungan dapat berupa lapangan, bukit; baik bukit alami maupun bukit buatan yang diperuntukkan sebagai jalur dan tempat evakuasi, bangunan yang ada, dan bangunan baru yang khusus dibuat untuk tujuan jalur dan tempat evakuasi.

Untuk mendapatkan parameter-parameter dalam menentukan jalur dan lokasi evakuasi tsunami di Kabupaten Gunungkidul adalah menggunakan code dan standar yang relevan yaitu FEMA P646. Pedoman FEMA P646 ini menyediakan penjelasan diantaranya mengenai analisa waktu, kecepatan dan jarak maksimum yang harus ditetapkan dengan mempertimbangkan jumlah dan tempat evakuasi, serta populasi pengunjung sebagai parameter penting agar keberadaan tempat evakuasi menjadi optimum dalam menampung penduduk sekitar hingga yang berada pada jarak maksimum.

Upaya penyediaan jalur dan tempat evakuasi sesuai dengan salah satu program/kegiatan utama pemerintah yang tertuang di dalam Masterplan Pengurangan
Risiko Bencana Tsunami untuk tahun 2013-2019 pada program ketiga, yaitu Pembangunan dan Peningkatan Tempat Evakuasi Tsunami (BNBP, 2012). Upaya ini sangat strategis untuk antisipasi bencana tsunami, mengingat penyelamatan diri secara vertikal ke tempat evakuasi perlu dilakukan jika waktu yang tersisa untuk penyelamatan diri (golden time) sangat pendek, dan untuk kawasan pantai yang padat penduduk serta padat bangunan.

Maksud dan Tujuan dari penelitian ini adalah untuk penentuan jalur dan tempat evakuasi tsunami pada Pantai Nguluran, Pantai Gesing, Pantai Butuh dan Pantai Ngedan di Kabupaten Gunungkidul menggunakan pedoman FEMA P646.

\section{METODE}

Obyek wisata adalah tempat atau keadaan alam yang memiliki sumber daya wisata yang dibangun dan dikembangkan sehingga mempunyai daya tarik dan diusahakan sebagai tempat yang dikunjungi wisatawan (DISBUDPAR, 2016).

Objek penelitian penentuan tempat evakuasi tsunami adalah Pantai Nguluran, Pantai Gesing, Pantai Butuh dan Pantai Ngedan di Kabupaten Gunungkidul, yang merupakan kawasan aktivitas manusia cukup tinggi baik dari sektor pariwisata dan sektor perikanan.

Dalam menganalisis jalur dan tempat evakuasi (TE) untuk identifikasi jalur dan tempat evakuasi tsunami, jaringan jalan merupakan bahan dasar dari analisis yang dilakukan. Berhubung tempat evakuasi (TE) dibutuhkan dalam proses evakuasi, maka analisis mengenai area evakuasi tersebut perlu dilakukan. Proses analisis dilakukan dengan terlebih dahulu menentukan area aman. Area aman dapat berupa area yang berada di luar jangkauan 
gelombang tsunami ataupun area yang berada di dalam area genangan tsunami. Untuk evakuasi yang dilakukan dengan mengarahkan pengungsi ke area yang berada di luar jangkauan tsunami, maka disebut evakuasi horizontal. Sedangkan evakuasi yang dilakukan dengan mengarahkan pengungsi ke area aman yang berada dalam area jangkauan tsunami dinamakan evakuasi vertikal.

Kegiatan mengumpulkan data dalam suatu penelitian sangat membutuhkan ketelitian, kecermatan, serta penyusunan program yang terinci. Hal ini mempunyai maksud agar diperoleh data yang benar-benar relevan dengan tujuan penelitian. Metode yang digunakan untuk mengumpulkan data tentang penentuan tempat evakuasi tsunami pada Pantai Nguluran, Pantai Gesing, Pantai Butuh dan Pantai Ngedan di Kabupaten Gunungkidul adalah data primer dan data sekunder dengan penjelasan berikut ini.

a. Data Primer

Data primer adalah data yang secara langsung diperoleh pada waktu penelitian, yaitu; observasi di lapangan dengan melakukan pengamatan dan pencatatan terhadap fenomena yang diteliti.

b. Data Sekunder

Data sekunder adalah data yang diperoleh dari hasil pengukuran, pencatatan, dan penyelidikan ataupun dari kegiatan pihak lain termasuk didalamnya laporan-laporan penyelidikan atau laporan kegiatan dari suatu kelompok studi maupun dari suatu instansi yang terkait dengan permasalahan tersebut.

Data sekunder antara lain adalah:

1) jumlah pengunjung maksimal pada masing-masing obyek wisata yang akan diteliti, yang didapatkan dari Dinas Pariwisata atau Badan Pusat Statistik Kabupaten Gunungkidul;
2) jenis dan lebar jalan yang berada di kawasan obyek wisata yang akan diteliti, lebar jalan digunakan sebagai konstrain dalam menentukan kecepatan berjalan penduduk sepanjang rute evakuasi. Lebar jalan ini mempangaruhi sejauh mana jalan yang dapat dilalui para pengungsi dalam waktu yang tersedia;

3) kerentanan tsunami meliputi ketinggian (elevasi) permukaan tanah, jarak dari garis pantai, kepadatan penduduk dan permukiman;

4) peta Topografi, peta ini digunakan untuk menentukan batas administrasi wilayah penelitian serta referensi dalam melakukan koreksi geometrik pada citra satelit;

5) peta Jaringan Jalan pada masingmasing obyek wisata, Peta ini menunjukkan jalan yang dapat dijadikan sebagai rute evakuasi;

c. Metode Dokumentasi

Analisa dokumentasi dilakukan untuk mengumpulkan data yang bersumber dari arsip dan dokumen yang ada di obyek-obyek wisata pantai di Gunungkidul. Teknik dokumentasi yaitu mencari data mengenai hal yang berupa catatan, buku, foto.

Dalam penelitian ini, data yang telah dikumpulkan, baik melalui penelitian lapangan maupun penelitian kepustakaan dianalisis secara kuantitatif yang dikombinasikan dengan kualitatif sebagai suplemen penjelasan dari kesimpulan yang didapat. Secara kuantitatif digunakan Google Earth, sedangkan secara kualitatif dengan menggunakan Pedoman FEMA P646. Tahapan analisis data pada penelitian melalui 5 langkah berikut ini.

1) Analisis sebaran populasi

Perkiraan jumlah dan distribusi populasi di wilayah obyek wisata sangat penting diketahui untuk perencanaan evakuasi, artinya tempat evakuasi tsunami dapat ditempatkan dengan tepat. Area 
pelayanan terkait kapasitas tempat evakuasi juga dapat diketahui, sehingga dapat diketahui kebutuhan jumlah dan kapasitas tempat evakuasi yang dibutuhkan, data sebaran populasi antara lain;

a. Jumlah penduduk pada masingmasing obyek wisata, meliputi lakilaki, perempuan, penyandang disabilitas, dan lain-lain.

b. Jumlah pengunjung maksimal pada masing-masing obyek wisata.

c. Jumlah dan jenis bangunan seperti rumah, sekolah, kantor, tempat ibadah, dan lain-lain pada masingmasing obyek wisata.

d. Ketinggian (elevasi) permukaan tanah, jarak dari garis pantai dengan menggunakan Aplikasi Altimeter dan Google Earth.

e. Proyeksi jumlah pengunjung.

$P_{n}=P_{0}(1+x)^{n}$

\section{Dimana:}

- Pn adalah proyeksi jumlah pengunjung pada tahun ke-n

- Po adalah jumlah pengunjung tahun awal

- $x$ adalah angka pertumbuhan jumlah pengunjung dari tahun ke tahun (\%)

- $n$ adalah tahun ke-n

2) Analisis waktu, kecepatan dan jarak evakuasi

Dalam rentang waktu perkiraan datangnya tsunami atau ETA (estimated time of arrival) tidak semua dapat digunakan sebagai waktu evakuasi, namun terdapat waktu untuk mendeteksi tsunami, waktu persiapan dan waktu untuk naik ke posisi aman.

Perhitungan secara empiris untuk analisa waktu, kecepatan dan jarak evakuasi dapat dilihat pada jarak maksimum tempat evakuasi berdasarkan waktu peringatan [9].

Perhitungan rumus ETA adalah:

ETA $=\frac{L}{V} . t$

Dimana:

- ETA adalah waktu tiba tsunami

- L adalah panjang jalur evakuasi

- $V$ adalah kecepatan orang berjalan lemah

- $t$ adalah faktor pengali waktu

3) Analisis kapasitas tempat evakuasi vertikal tsunami dan tempat evakuasi vertikal tsunami eksisting.

Jika teridentifikasi terdapat lokasi evakuasi tsunami yang aman kemudian di lakukan analisa kapasitas tempat evakuasi vertikal tsunami yang meliputi kebutuhan ruang evakuasi dan efektifitas ruang evakuasi. Jika teridentifikasi lokasi evakuasi tsunami itu suatu bangunan, maka ditentukan dengan kriteria tempat evakuasi vertikal tsunami berdasarkan FEMA P646.

4) Digitasi peta.

Proses ini dilakukan untuk mendapatkan peta tematik yang akan menjadi data turunan dengan menggunakan Google Earth kemudian hasilnya digunakan sebagai acuan dalam pembuatan jalur evakuasi.

\section{HASIL DAN PEMBAHASAN}

Peta evakuasi tsunami Pantai Gesing yang dibuat oleh Badan Penanggulangan Bencana Daerah (BPBD) Kabupaten Gunungkidul pada tahun 2012, kemudian dengan aplikasi Google Earth peta tersebut dicari panjang jalur evakuasi dari pantai ketempat titik aman pertama dan luas kapasitas tempat evakuasi tsunami masing-masing objek wisata, hal lebih rinci dapat dilihat pada Tabel 2. 
Identifikasi Jalur... (Limpat/ hal 24-37)

Tabel 2. Rincian Peta Evakuasi tsunami BPBD Kabupaten Gunungkidul

\begin{tabular}{lcccc}
\hline $\begin{array}{c}\text { Nama } \\
\text { Pantai }\end{array}$ & $\begin{array}{c}\text { Panjang } \\
\text { Jalur } \\
(\mathbf{m})\end{array}$ & $\begin{array}{c}\text { Tinggi } \\
\text { Titik } \\
(\mathbf{m})\end{array}$ & $\begin{array}{c}\text { Luas } \\
\text { Tempat } \\
\left(\mathbf{m}^{2}\right)\end{array}$ & $\begin{array}{c}\text { Waktu } \\
\text { Tiba } \\
\text { Tsunami } \\
(\mathbf{m e n i t})\end{array}$ \\
\hline Nguyahan & 3567 & 50 & \pm 500 & 51,67 \\
\hline Ngobaran & 2359 & 100 & \pm 500 & 43,96 \\
\hline Ngrenehan & 2634 & 100 & \pm 500 & 49,08 \\
\hline
\end{tabular}

1) Penentuan Lokasi Titik Aman/evakuasi dengan Altimeter

Altimeter adalah sebuah alat untuk mengukur ketinggian suatu titik dari permukaan laut. Dalam penelitian ini untuk menentukan ketinggian titik kumpul evakuasi sebagai titik aman pertama kali akibat tsunami dengan menggunakan aplikasi altimeter. Pengambilan titik kumpul ditentukan ketinggiannya minimal 25 Meter diatas permukaan laut [1] sebagai titik aman pertama untuk evakuasi tsunami dengan mempertimbangkan potensi wilayah untuk tempat evakuasi dan jarak tidak terlalu jauh dari lokasi pantai. Sebagaimana ditunjukkan dalam Tabel 3.

Tabel 3. Ketinggian Titik aman pertama/kumpul

\begin{tabular}{lc}
\hline Nama Pantai & $\begin{array}{c}\text { Ketinggian Titik Kumpul } \\
\text { AMSL }(\mathbf{m})\end{array}$ \\
\hline Nguyahan & 28 \\
\hline Ngobaran & 28 \\
\hline Ngrenehan & 28 \\
\hline
\end{tabular}

Penggunaan aplikasi altimeter dan lokasi tempat evakuasi/titik kumpul pada masingmasing pantai dapat dilihat lebih rinci pada Gambar 7., Gambar 8., Gambar 9.

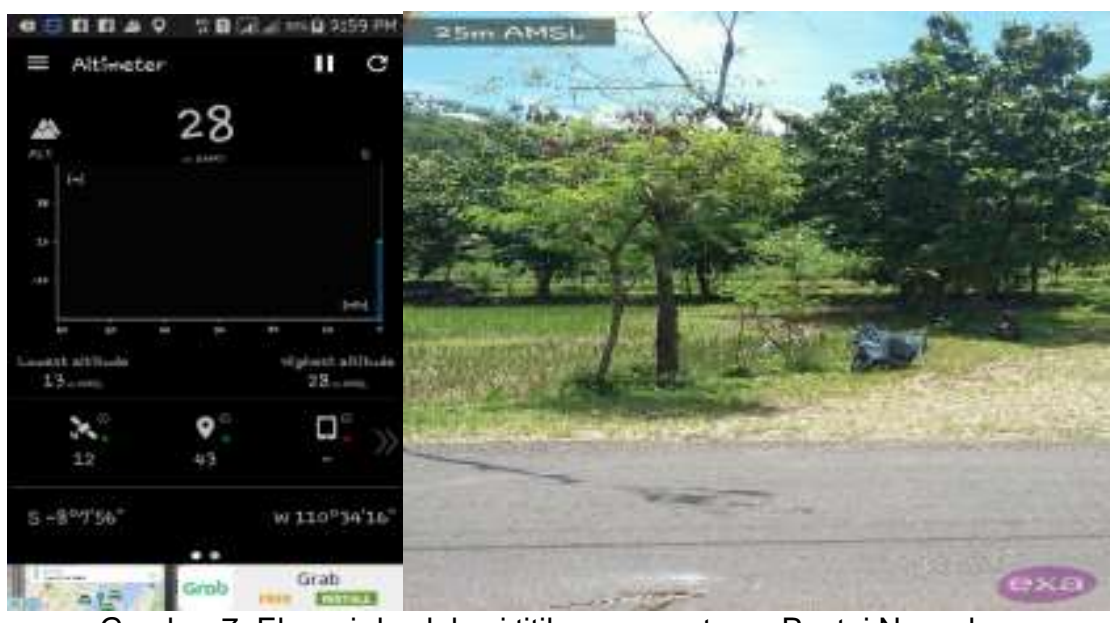

Gambar 7. Elevasi dan lokasi titik aman pertama Pantai Nguyahan

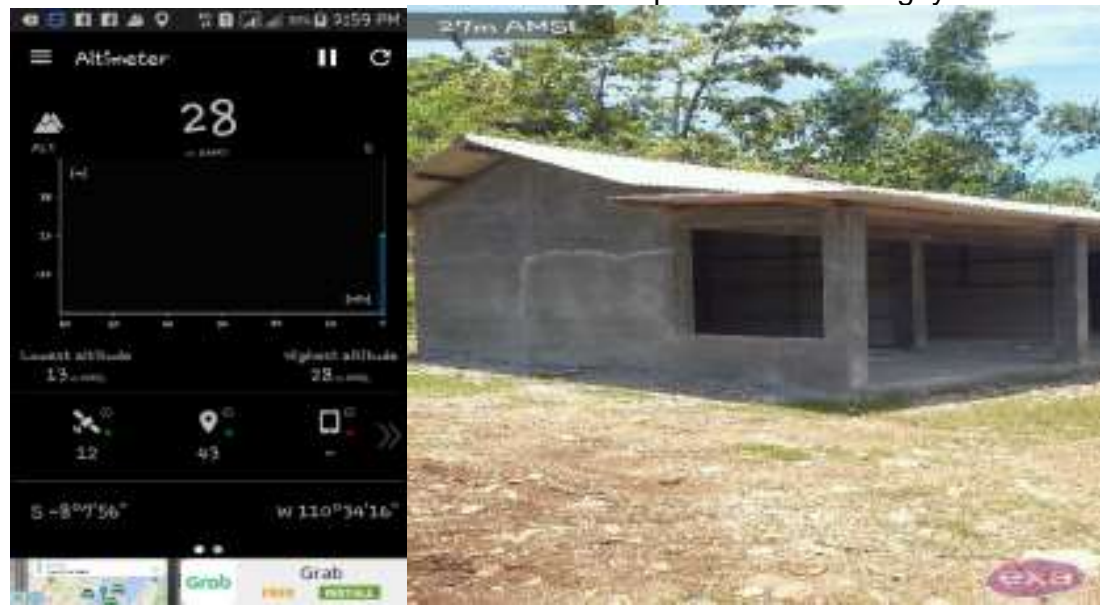

Gambar 8. Elevasi dan lokasi titik aman pertama Pantai Ngobaran 


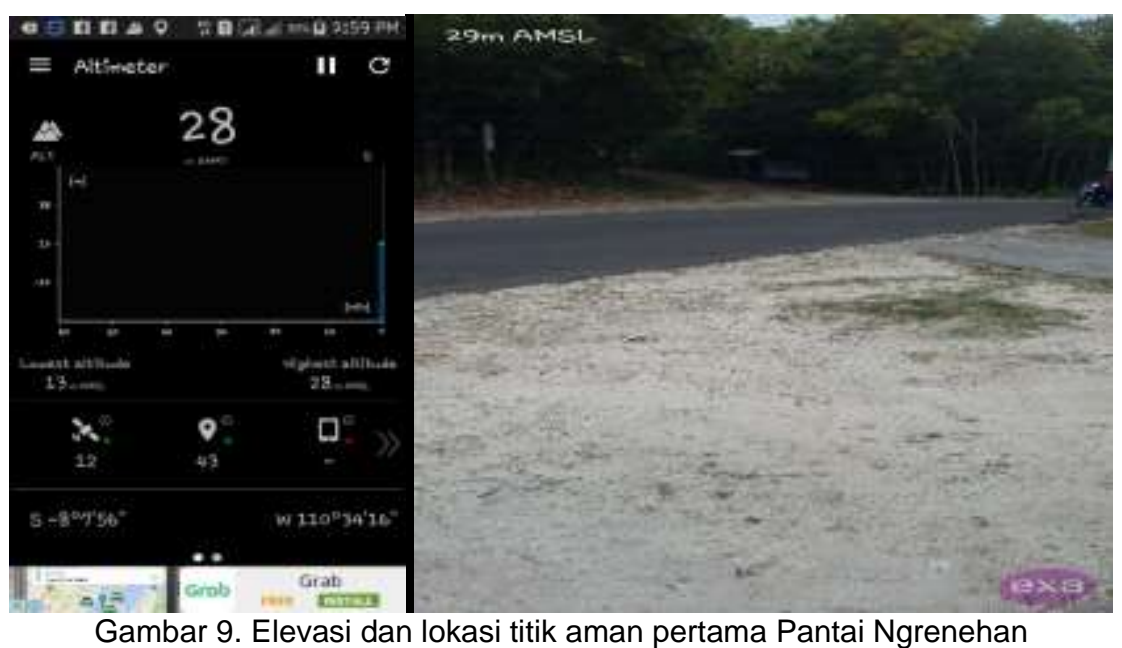

2) Data dan Analisis Proyeksi Jumlah Pengunjung Tahun 2027

Seiring banyaknya wisatawan yang berkunjung pada objek wisata pantai di Kabupaten Gunungkidul, hal tersebut menjadi potensi korban tsunami sangat besar. Tempat evakuasi tsunami saat ini yang disediakan oleh pemda, jika kita hitung perbandingan dengan jumlah pengunjung objek wisata pantai pada tahun 2017, kapasitas/kebutuhan akan ruang evakuasi masih belum mencukupi. Diketahui bahwa angka pertumbuhan jumlah pengunjung objek wisata pantai mencapai 30\% (BPS, 2016). Angka pertumbuhan tersebut dijadikan acuan umtuk menghitung proyeksi jumlah pengunjung 10 tahun yang akan datang, dengan asumsi angka pertumbuhan tersebut sama setiap tahunnya. Dengan menggunakan rumus diatas, maka dapat dihitung proyeksi jumlah pengunjung objek wisata pantai 10 tahun yang akan datang dari Tahun 2017. Sebagaimana ditunjukkan dalam Tabel 4.

\begin{tabular}{|c|c|c|}
\hline Pos Retribusi & Tahun 2017 & Tahun 2027 \\
\hline Ngobaran & \multirow[t]{2}{*}{18.369} & \multirow[t]{2}{*}{253.232} \\
\hline Ngrenehan & & \\
\hline Total & 18.369 & 253.232 \\
\hline
\end{tabular}

3) Penentuan Jalur, Jarak dan luasan titik kumpul evakuasi tsunami

Dalam menentukan jalur evakuasi, jarak dan luasan titik kumpul dengan menggunakan aplikasi google earth, sehingga akan didapat langsung jalur, jarak dan luasan titik kumpul evakuasi tsunami. Sebagaimana ditunjukkan pada Tabel 5.

Dengan menggunakan aplikasi google earth, maka didapat jarak dan luasan titik kumpul evakuasi tsunami pada masingmasing pantai. Sebagaimana ditunjukkan pada Gambar 10. sampai dengan Gambar 11.

Tabel 5. Ketinggian, Jarak dan Luasan titik aman pertama evakuasi tsunami

\begin{tabular}{lccc}
\hline $\begin{array}{c}\text { Nama } \\
\text { Pantai }\end{array}$ & $\begin{array}{c}\text { Ketinggian } \\
\text { Titik Kumpul } \\
\text { AMSL }(\mathbf{m})\end{array}$ & $\begin{array}{c}\text { Jarak } \\
(\mathbf{m})\end{array}$ & $\begin{array}{c}\text { Luas } \\
\left(\mathbf{m}^{2}\right)\end{array}$ \\
\hline Nguluran & 28 & 549 & 647 \\
\hline Butuh & 28 & 537 & 647 \\
\hline Jogan & 28 & 812 & 647 \\
\hline
\end{tabular}

Tabel 4. Proyeksi jumlah Pengunjung Tahun 2027

\begin{tabular}{lll}
\hline Pos Retribusi & Tahun 2017 & Tahun 2027 \\
\hline Nguyahan & & \\
\hline
\end{tabular}




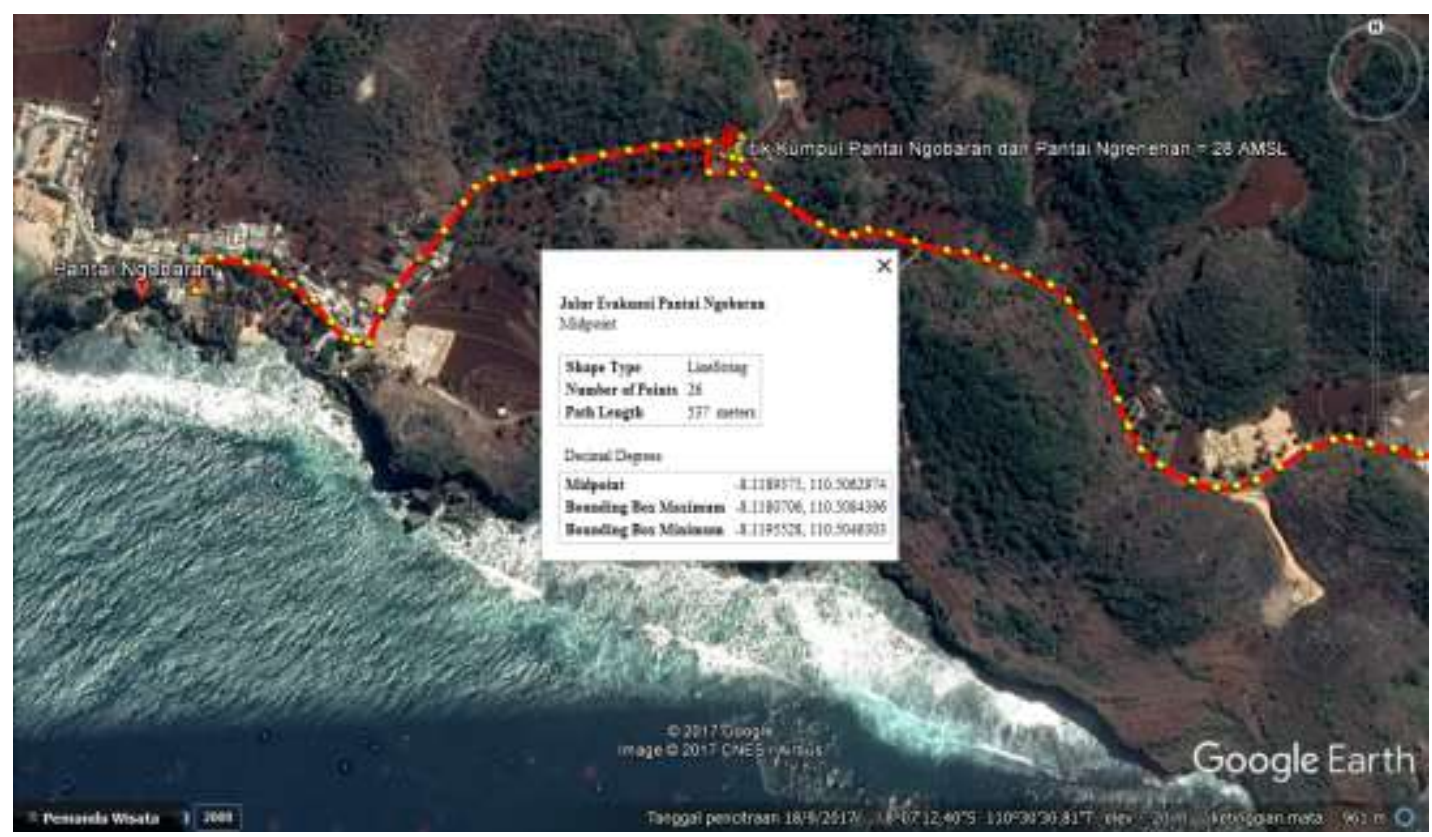

Gambar 10. Jarak/panjang Jalur evakuasi/titik aman pertama Pantai Ngobaran

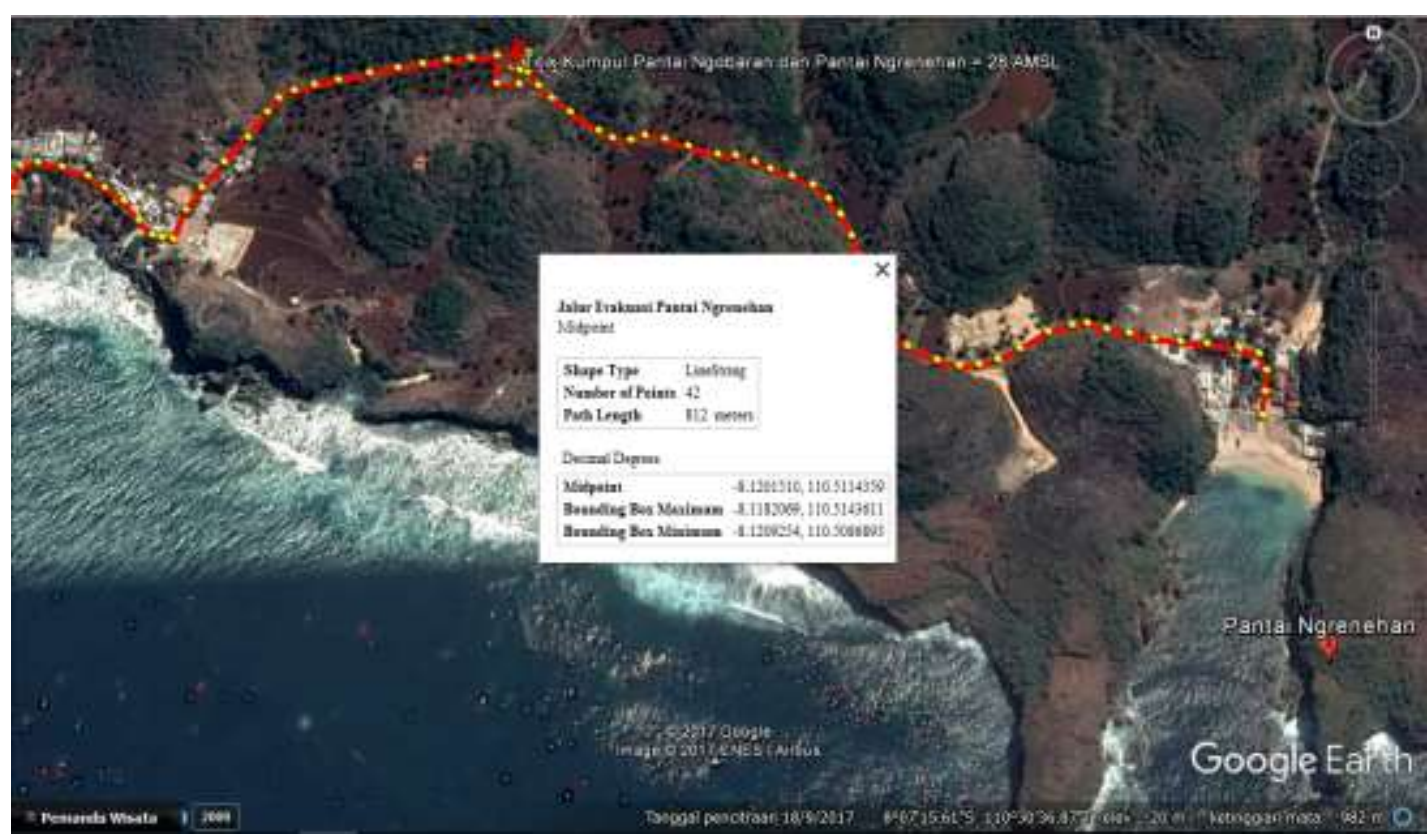

Gambar 11. Jarak/panjang Jalur evakuasi/titik aman pertama Pantai Ngrenehan

4) Penentuan waktu kedatangan/waktu tiba tsunami

Kemampuan rata-rata orang sehat dapat berjalan dengan kecepatan 6,44 $\mathrm{km}$ per jam dan kecepatan orang berjalan dengan keterbatasan fisik 3,22 $\mathrm{km}$ per jam, maka bisa ditentukan waktu kedatangan/waktu tiba tsunami (FEMA P646, 2008). Sebagaimana ditunjukkan pada Tabel 6 .
Tabel 6. Waktu peringatan berdasarkan jarak titik aman

\begin{tabular}{lccc}
\hline $\begin{array}{l}\text { Nama } \\
\text { Pantai }\end{array}$ & $\begin{array}{c}\text { Jarak } \\
(\mathbf{m})\end{array}$ & $\begin{array}{c}\text { Kecepatan } \\
\text { orang } \\
\text { berjalan } \\
\text { (lemah) } \\
\text { (km/jam) }\end{array}$ & $\begin{array}{c}\text { Waktu } \\
\text { kedatangan } \\
\text { Tsunami } \\
\text { (menit) }\end{array}$ \\
\hline Nguyahan & 549 & 3.22 & 10,23 \\
\hline Ngobaran & 537 & 3,22 & 10,01 \\
\hline Ngrenehan & 812 & 3,22 & 15,13 \\
\hline
\end{tabular}


5) Penentuan kebutuhan ruang titik kumpul evakuasi/aman pertama tsunami

Kebutuhan ruang untuk evakuasi tsunami adalah $0,5 \mathrm{~m}^{2}$ per orang, dengan kata lain setiap $1 \mathrm{~m}^{2}$ dapat menampung 2 orang. Pengungsi diasumsikan duduk tanpa kursi (bersila atau kaki menekuk ke depan) selama beberapa jam menunggu waktu kritis gelombang tsunami mereda. Posisi duduk tanpa kursi dan duduk bersila posisi duduk santai dengan kaki ditekuk ke depan membutuhkan ruang seluas $0,47 \mathrm{~m}^{2}$ s.d $0,55 \mathrm{~m}^{2}$ per orang (FEMA P646, 2008). Maka kebutuhan ruang titik kumpul evakuasi tsunami dapat dilihat dalam Tabel 7.
Tabel 7. Kebutuhan ruang titik kumpul/aman pertama

\begin{tabular}{|c|c|c|c|}
\hline $\begin{array}{l}\text { Nama } \\
\text { Pantai }\end{array}$ & $\begin{array}{l}\text { Luas } \\
\text { (m2) }\end{array}$ & $\begin{array}{l}\text { Kebutuhan } \\
\text { ruang } \\
\text { (orang) (1 } \\
\mathrm{m}^{2}=2 \\
\text { orang) }\end{array}$ & $\begin{array}{c}\text { Jumlah } \\
\text { pengunjung } \\
\text { maksimal } \\
\text { (per hari) } \\
\text { (pengunjung) }\end{array}$ \\
\hline Nguyahan & 647 & 1.294 & $18.369 / 8=$ \\
\hline Ngobaran & 647 & 1.294 & 2.296 \\
\hline \multirow[t]{2}{*}{ Ngrenehan } & 647 & 1.294 & \\
\hline & 1.941 & 3.882 & $\begin{array}{c}18.369 / 8= \\
2.296\end{array}$ \\
\hline
\end{tabular}

Berdasarkan data dari Tabel 7. secara keseluruhan ruang titik aman pertama/kumpul yang ditentukan sudah memenuhi syarat, untuk menampung jumlah pengungsi jika terjadi bencana tsunami.

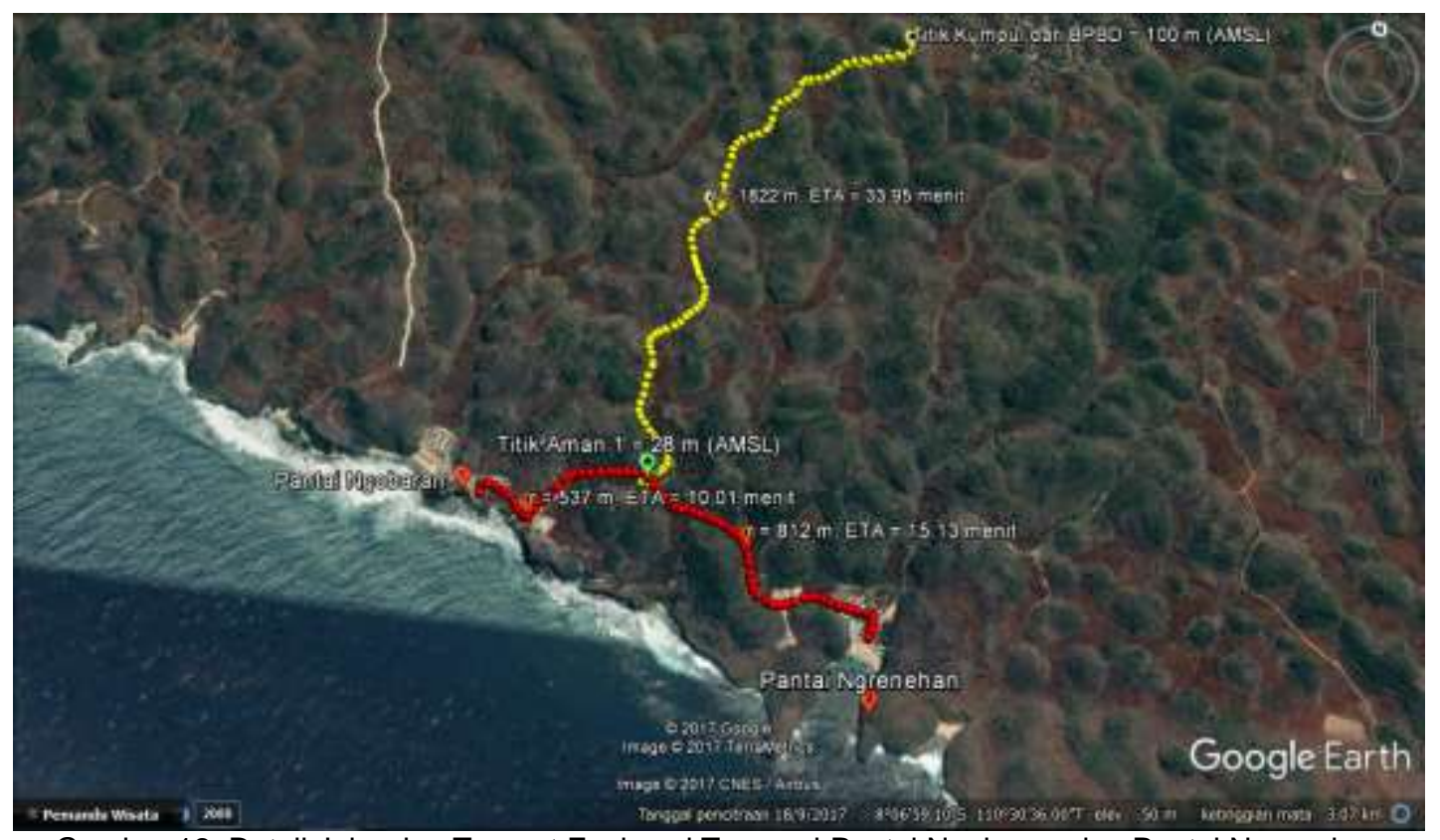

Gambar 12. Detail Jalur dan Tempat Evakuasi Tsunami Pantai Ngobaran dan Pantai Ngrenehan

Sebagaimana ditunjukkan dalam Tabel 2. rincian peta evakuasi tsunami BPBD Kab. Gunungkidul, bahwa jarak evakuasi yang ditempuh membutuhkan waktu yang lama, kebutuhan tempat evakuasi masih belum mencukupi untuk jumlah korban jika terjadi tsunami. Untuk itu dalam penelitian ini, bahwa ketinggian tsunami mencapai ketinggian 25 meter (BAKORNAS, 2007), kemudian dijadikan acuan untuk menentukan titik aman pertama dalam proses penyelamatan jika terjadi tsunami. Ketinggian titik aman tersebut bisa dilihat dalam Tabel 1.

Untuk penentuan jarak maksimum berdasarkan waktu peringatan, ilustrasi perhitungannya, bila kecepatan orang berjalan dengan keterbatasan fisik 3,22 $\mathrm{km}$ per jam dan apabila waktu evakuasi

INERSIA, Vol. XVI No. 1, Mei 2020 
yang ada (golden time) setelah peringatan tsunami adalah 30 menit, sehingga Tempat Evakuasi (TE) dapat ditempatkan pada jarak maksimum $1,61 \mathrm{~km}$ dari titik berangkat. Hal ini akan menghasilkan sebuah jarak maksimum rata-rata adalah 3,22 km diantara dua Tempat Evakuasi (TE). Demikian pula, asumsi waktu peringatan 15 menit, Tempat Evakuasi (TE) akan berlokasi pada jarak maksimum $0,8045 \mathrm{~km}$ dari titik berangkat, dan 1,61 km jarak diantara dua Tempat Evakuasi (TE). Waktu peringatan yang lebih panjang akan mempersyaratkan jarak yang lebih jauh. Sebagaimana ditunjukkan pada Tabel 6 . waktu peringatan berdasarkan jarak titik kumpul.

Untuk penentuan lokasi evakuasi vertikal mempertimbangkan perilaku evakuasi dan tempat tinggi yang alami, ketika menentukan struktur evakuasi vertikal alami, perilaku pengungsi harus dipertimbangkan. Sebagian besar mereka populasi masyarakat pesisir telah dididik untuk pergi ke tempat yang tinggi. Kecenderungan alami untuk pengungsi akan bermigrasi jauh dari pantai. Oleh karena itu struktur evakuasi vertikal harus terletak di sisi pedalaman zona evakuasi dan harus mengambil keuntungan dari topografi alami yang akan cenderung untuk menarik pengungsi ke arah mereka. Dalam penelitian ini hasil ketinggian dan jarak yang diperoleh sudah mempetimbangkan ketentuan tersebut. Sebagaimana ditunjukkan pada Tabel 5. Ketinggian, Jarak dan Luasan titik kumpul evakuasi tsunami. Efek samping bahaya di sekitar setiap bangunan menjadi pertimbangan dalam penentuan lokasi struktur evakuasi vertikal. potensi bahaya bangunan termasuk gelombang, puingpuing dibawa melalui gelombang, Bila mungkin, struktur evakuasi vertikal harus berada jauh dari potensi bahaya yang dapat mengakibatkan kerusakan tambahan untuk struktur dan keselamatan bagi penghuni. Mungkin karena terbatasnya ketersediaan bangunan, dan pembatasan perjalanan dan mobilitas penduduk dalam masyarakat, beberapa struktur evakuasi vertikal perlu berada di tempat yang akan dianggap kurang ideal.

Jalur evakuasi mengarahkan untuk menjauhi arah gelombang dan harus diindikasikan dengan jelas melalui ramburambu, seperti menjauhi garis pantai; menghindari melewati jembatan, memanfaatkan jalur eksisting, menuju jalan dengan lebar yang lebih besar agar tidak terjadi bottle neck (lintasan sempit), menghindari hambatan atau rintangan, pergerakan massa setiap blok diarahkan agar tidak tercampur dengan blok lainnya untuk menghindari kemacetan. Aksesibilitas; dilarang parkir kendaraan di jalan sehingga tidak terjadi penumpukan atau kemacetan di jalan utama. Dalam hal tersebut, penelitian ini sudah mempertimbangkan baik aksesibilitasnya maupun menjauhi garis pantai untuk penentuan jalur lokasi evakuasi tsunami.

Untuk evakuasi horizontal, maka yang dijadikan sebagai titik evakuasi adalah perpotongan antara jalan dengan batas rendaman tsunami. Namun dalam penelitian tidak ada peta genangan gelombang tsunami, maka yang dilakukan adalah menentukan titik dengan altimeter secara acak, akan tetapi mempertimbangkan jarak, ketinggian yang aman dari gelombang tsunami, Selanjutnya dari titik-titik tersebut di buat service area sebesar berapa menit, artinya ditentukan lokasi mana saja yang dapat mencapai titik evakuasi tersebut dalam waktu 60 menit. 60 menit adalah waktu yang tersedia untuk melakukan evakuasi.

Hasil pembuatan peta evakuasi yang dilakukan oleh Badan Penanggulangan 
Bencana Daerah (BPBD) Kabupaten Gunungkidul bisa dilihat pada lampiran, sebagai pembanding dari hasil penelitian yang dilakukan.

Perbandingan secara garis besar adalah bahwa dalam penelitian ini lokasi/titik aman tidak sama dengan lokasi penentuan titik aman pada peta evakuasi tsunami yang ada dalam BPBD (BAKORNAS, 2007). Jika dalam penelitian ini lokasi/titik aman evakuasi tsunami nantinya akan digunakan sebagai penyelamatan pertama korban tsunami dengan mempertimbangkan waktu kedatangan tsunami, akan tetapi dalam BPBD menggunakan fasilitas umum yang walaupun jaraknya jauh dan mengindahkan waktu kedatangan tsunami.

\section{SIMPULAN}

Berdasarkan hasil penelitian yang dilakukan diperoleh beberapa kesimpulan. Kesimpulan tersebut adalah: 1) Nilai ketinggian titik kumpul 25 meter dari permukaan laut menjadi dasar untuk menyelamatkan diri, jika dihubungkan dengan kecepatan orang berjalan (kondisi lemah), maka waktu kedatangan/waktu tiba tsunami didapat tidak lebih dari 1 jam, hal ini masih dalam batasan sesuai dengan Federal Emergency Management Agency (FEMA P-646, 2008), luasan titik kumpul evakuasi tsunami jika dihubungkan dengan jumlah pengunjung maksimal antara tahun 2014-2017, maka titik evakuasi tersebut secara keseluruhan dapat menampung jumlah pengunjung/pengungsi jika tsunami terjadi; dan 2) Lokasi/ titik aman evakuasi dalam penelitian tidak sama dengan lokasi penentuan titik aman pada peta evakuasi tsunami yang ada dalam BPBD. Dalam penelitian ini lokasi/ titik aman evakuasi tsunami bisa digunakan penyelamatan pertama korban tsunami dengan mempertimbangkan waktu kedatangan tsunami, akan tetapi dalam BPBD untuk penampungan korban tsunami menggunakan fasilitas umum walaupun jaraknya jauh dan mengindahkan waktu kedatangan tsunami.

\section{DAFTAR RUJUKAN}

BAKORNAS, 2007. Pengenalan Karakteristik Bencana dan Upaya Mitigasinya di Indonesia. Edisi Kedua. Direktorat Mitigasi, Lakhar Bakornas PB. Jakarta.

BMKG, 2010. Rencana Strategis Badan Meteorologi, Klimatologi, Dan Geofisika Tahun 2010-2014, Jakarta.

BNPB, 2009. Rencana Nasional Penanggulangan Bencana Tahun 2010-2014, Jakarta.

BNPB, 2012. Master Plan Pengurangan Risiko Bencana Tsunami, Jakarta.

BNPB, 2014. Rencana Nasional Penanggulangan Bencana Tahun 2015-2019, Jakarta.

BPBD, 2012. Pengurangan Risiko Bencana Kabupaten Gunungkidul, Gunungkidul.

BPS, 2016. Kabupaten Gunungkidul Dalam Angka 2016, Badan Pusat Statistik, Gunungkidul.

DISBUDPAR, 2016. Potensi Kebudayaan dan Kepariwisataan Kabupaten Gunungkidul, Gunugkidul.

FEMA P646, 2008. Guidelines for Design of Structures for Vertical Evacuation

INERSIA, Vol. XVI No. 1, Mei 2020 
Identifikasi Jalur... (Limpat/ hal 24-37)

from Tsunamis. California, Amerika Serikat: Federal Emergency Management Agency (FEMA).

Iman Satyarno, 2012. Pemanfaatan Bangunan Yang ada sebagai Fasilitas Evakuasi Vertikal pada Daerah Potensi Tsunami di Indonesia dalam F. Wang et al. (eds.), 2013. Progress of GeoDisaster Mitigation Technology in Asia, Environmental Science and Engineering, DOI: 10.1007/978-3-

642-29107-4_14, @Springer-Verlag Berlin Heidelberg.

Iman Satyarno, 2013. Penilaian terhadap Gempa dan Tsunami 2004/2011 di Indonesia dan Jepang: Pelajaran dan Tantangan ke Depan dalam The 1st International Conference on Sustainable Civil Engineering Structures and Construction Materials (SCESCM), Proceeding, Universitas Gadjah Mada, Yogyakarta. 